\title{
An Impression on Over Modulation Strategy in Inverter
}

\author{
Raghuraj kumar', Bharat Modi', Baibhav Bishal ${ }^{1}$, Mahendra Lalwani ${ }^{2}$ \\ ${ }^{1}$ Department of Electrical Engineering, Swami Keshvanand Institute of Technology, Management \& Gramothan, Jaipur- \\ 302017 (INDIA) \\ ${ }^{2}$ Department of Electrical Engineering, Rajasthan Technical University \\ Kota-324010(India) \\ Email: raghurajk39@gmail.com,bharatalone@gmail.com, baibhavajit@gmail.com \\ Received 28.07.2021, received in revised form 19.08.2021, accepted 23.08.2021 \\ doi: 10.47904/IJSKIT.11.2.2021.40-49
}

\begin{abstract}
Energy production has continuously now become center of attraction as the global energy problem has become more significant. The Pulse Width Modulation (PWM) inverter's creation and application are critical to renewable energy technologies. Furthermore, one of the most essential concerns for PWM Inverters is Over Modulation (OM) performance. OM technology improves the primary voltage and current, reduces device variable reaction time, \& increases the normal operating zone.The harmonic current issue, the difficulty of the overmodulation approach, and the seamless transition between linear and overmodulation areas are all emphasised as important issues with the overmodulation strategy. The merits and downsides of common overmodulation methods are contrasted and explained in this paper.
\end{abstract}

Keywords- OM-Over Modulation, PWM-Pulse width modulation, SV-Space vector, O/P-Output, VV- Voltage Vector.

\section{INTRODUCTION}

Energy deficiency is becoming one of the most important challenges as a result of global financial and social events. As coal, oil, gaseous petrol, and other inorganic energy sources become exhausted, citizens are rushing to investigate and use latest power sources as an example sunlight, air, flowing energy, and power devices [1]. Inexhaustible energy innovation has recently attracted a growing amount of attention from experts throughout the world [2]. Many exchanging current (AC) speed guideline frameworks rely on the utilization of variable recurrence speed guideline innovation [3] thanks to the help of a concentrated economy. In it is critical to improving the inverter's force use and working proficiency in this manner. Furthermore, the PWM inverter configuration is frequently used in the environmentally friendly power source matrix linked age framework to achieve a broad operational range. PWM inverters are commonly divided into Voltage Source Inverters (VSI) and Current Source Inverters (CSI). There are two separate PWM modulation schemes for VSI. The first is based on transporter correlation, while the second is based upon the voltage space-vector and is termed as Space-Vector
PWM (SV-PWM) [4]. SV-PWM is broadly used in elite speed control frameworks, adaptable control of vector arrangement, and other applications due to its simple execution, high voltage usage, low $\mathrm{o} / \mathrm{p}$ current symphonious segments, and low wave force [5]. The essential abundance of the most extreme output voltage for VSI with SV-PWM [6] be 15.5 percent higher than that of Sinusoidal PWM (SPWM) [7] in the direct adjustment district shown in Fig.1. In operation, the inverter might work away from the linear modulation zone, toward the inside OM mode, resulting in voltage and current distortion, as well as closures in six-venture activity. Nonetheless, in this circumstance, the output primary voltage abundancy is $2 \mathrm{Vdc} / \Pi$ [8], [9]. For optimization techniques, a $10 \%$ rise in voltage level is definitely advantageous. That is why the persuasive OM system has garnered greater attention [10]-[13]. There are two types of old-style modulation approaches. The single-mode control system [14-16], [17] and the dual-mode control system [18-20], [17]. In [14], a single-mode system was developed that considered the modulation area as a whole, avoiding the calculation's handover. In [19], offered a dual-mode OM approach as an example the total OM measure is divided into two sections, according to the particular balancing proportion: OM mode I and mode II. The abundancy of output voltage is modified in OM mode I only, whereas both the sufficiency and the stage point are changed in OM mode II. This methodology guarantees that the output voltage of the inverter is communicated properly from straight adjustment area to six-step mode.

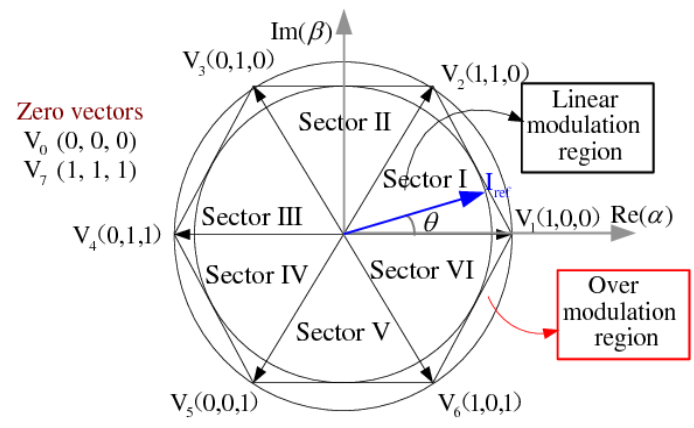

Fig. 1 Modulation area of voltage source inverter [34] 
In any situation, the standard dual mode will be used. The technique has the drawbacks of computational burden and separateness processing of information for the OM process, the piecewise fitting direct investigation is used to solve the problem [20]. Another intriguing solution based upon the superposition rule is presented in [22] [23], which is used to increases coherence and therefore reduces the complicated disconnected calculation and look-into measure. The OM procedures, on the other hand, can be divided into an open loop [15, 19, 20] [25] and close loop procedures [22] [24] [26] depending on the control cycle that establishes a close loop. In [20] the open-loop techniques considering stability among the multifarious nature for control calculation and manage the accuracy. Furthermore, the closeloop methodology is capable of comprehending the attributes of programmed pay. Because the neighboring loop technique was enhanced and streamlined within the OM area II, it now offers the benefits for simple computation, high precision, low THD, and so on. The close loop methodology has the best framework execution and the greatest application reach so far. The amount of stages increases as the progress. A regular progression toward the OM technique for staggered inverters can be seen in fig 2. CSI-SV-PWM. [27] Presents a SVPWM OM strategy or its use in a 3-level inverter. An OM method based upon vector aggregate was introduced in [23], which can improve to a certain momentary perfection when biased from a round direction and the direction for the hexagon within the segment super -imposed. The inverter's output current deformation is prompted by the OM methodology [28]. Because of its distinct characteristics, such the same as a variable information power factor, simple equal activity, and inward short out assurance [30], the CSI is commonly used for mechanical domains, particularly in high and medium force requiremments [29]. CSI's SV-PWM is similar to VSI's, except with additional one zero vector.

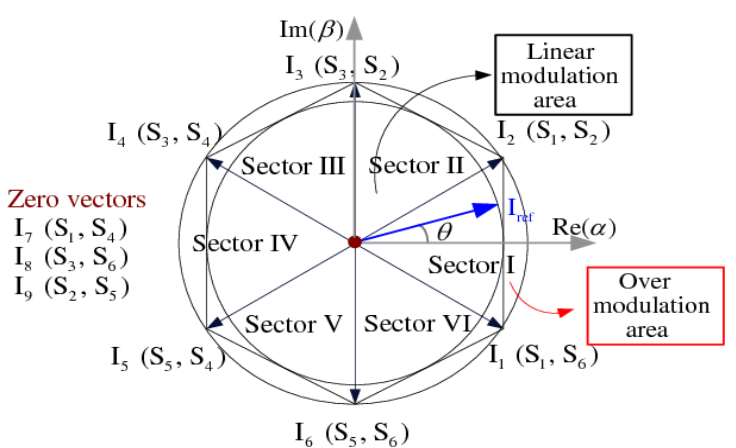

Fig. 2 CSI- pwm trajectory [31]

Fig 2 [31] shows the CSI-direction SV-PWMs. If the CSI moves outside the direct adjustment zone, it faces several issues that are comparable to those faced by the VSI. To this point for current source inverters, there are principally two approaches for OM strategies. The dual-mode OM technique [32] and the Block OM procedure [33] are the two techniques. In [32], the CSI offered a dual mode technique that had roughly the same properties as the VSI's dual-mode OM procedure [34]. Zhang et. al. presented the square finished balance approach, which has the advantages of being simple to calculate, having a high transient and consistent state reaction, and having a low total harmonic distortion of framework sided current. On three-level CSI, both of these techniques are employed, while the OM of staggered CSI requires further investigation.

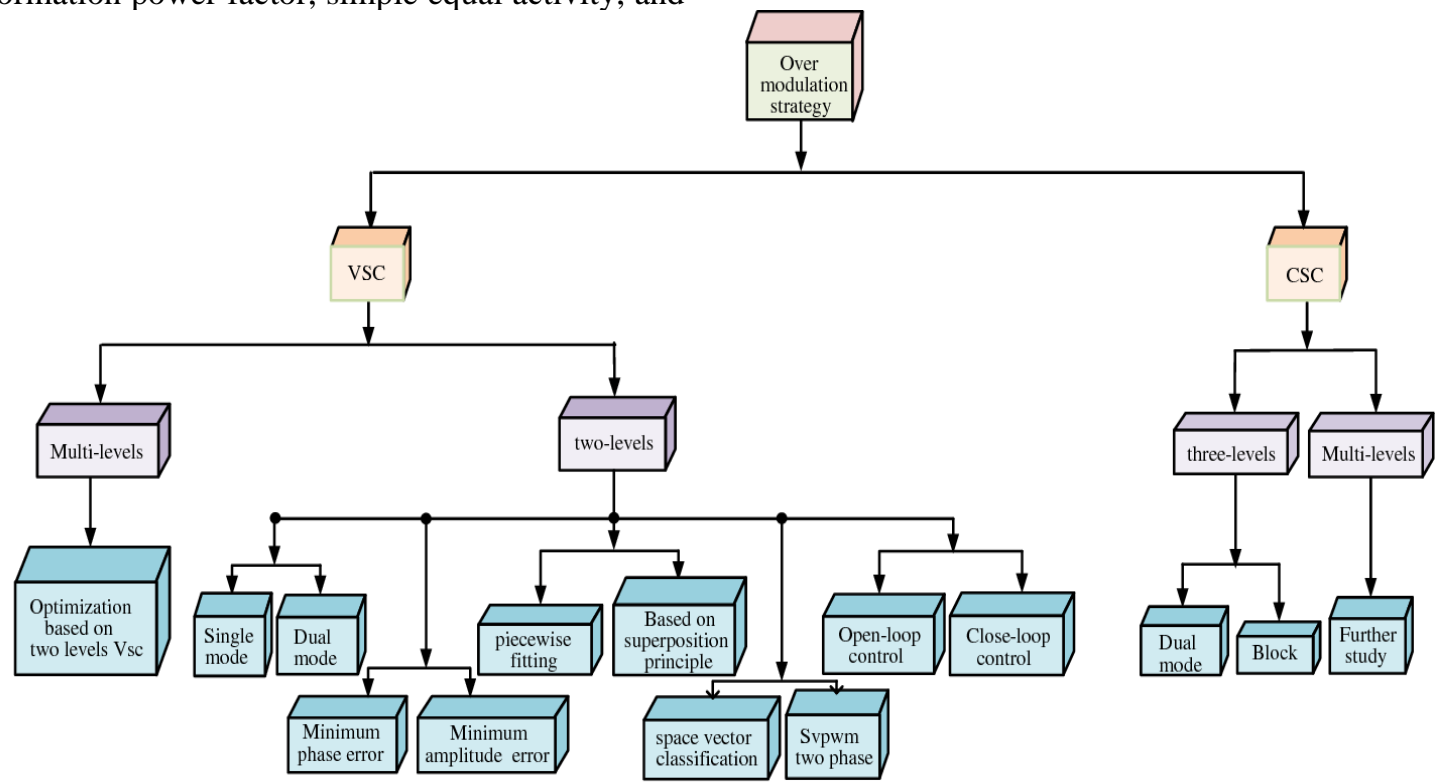

Fig. 3 OM (Over Modulation) scheme for VSI and CSI 


\section{OM (OVER MODULATION) TECHNIQUES FOR VSI}

The general OM method for VSI is demonstrated in this portion. If the measured $\mathrm{VV}$ is above the hexagon limit, the framework cannot be effectively managed. In every instance, the OM approach can shift the vector of overload component \& reverse direction of the resultant VV. The OM system's execution stream is described in [25]. The modulation coefficient $\mathrm{m}$ is equal to:

$$
m=\left|V_{\text {ref }}\right|\left(\frac{2}{\pi}\right) \cdot V_{d c}
$$

\subsection{Single mode control strategy}

To extricate the cycle and prevent the controlled precision loss, the primary single-mode process is used throughout the whole OM zone. The output VV remains just at fundamental vectors with a staging point equal to $\mathrm{a}_{\mathrm{g}}$ while measured $\mathrm{VV}$ above from hexagon limit, which is shown in fig. 4. The OM area's terminal VV would not be acquired till the measured VV passes through the hexagon again.As stated by typical adjustment procedure. The framework output VV direction in the OM zone which can be seen in Fig. 4.

As the preceding control procedure demonstrates, as soon as the framework's o/p VV is confined toward hexagon, its plentifulness of the real output reference voltage be still equivalent to that of the references VV.

$$
|\mu|=\left|V_{\text {ref }}\right|
$$

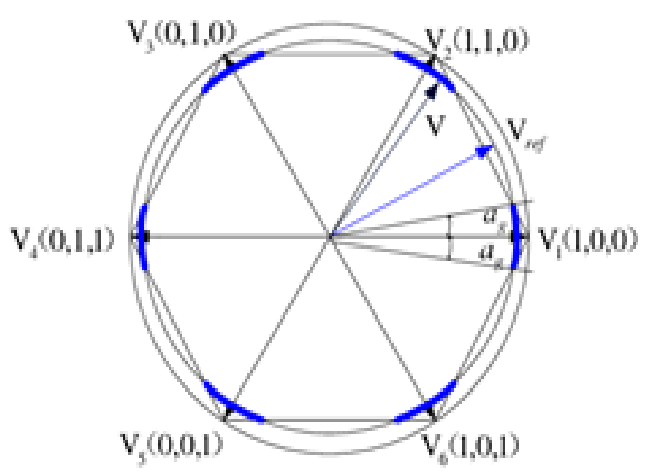

Fig. 4 Single-mode over-modulated voltage traces for single mode [14]

The output VV remains stationary whenever the measured VV attempted to move through the hexagon limit. For example, assume Sector I. When if the staging point is among $\mathrm{a}_{\mathrm{g}}$ and $\Pi / 6$, the true output VV's stage point $a_{g}$ is preserved. The stage point ag can be obtained using a mathematical connection [14].

$$
\cos \left(\frac{\pi}{6}-a_{g}\right)=\frac{\left\{\sqrt{3} \cdot \frac{1}{3 v_{d c}}\right\}}{\left|V_{\text {ref }}\right|}
$$

The real output VV stays at (ח/3-ag) point when the stage point is between $\Pi / 6$ and $\left(\Pi / 3-a_{g}\right)$, as evidenced by the symmetry.

\subsection{Dual mode control techniques}

A dual-mode approach is presented to overcome the single-mode system's weakness of high symphonious substance of output voltage. The OM district is isolated in the OM area $\mathrm{I}(0.9069<\mathrm{m}<0.9517)$ and OM area II $(0.9517<\mathrm{m}<1)$. The differences among both-mode and single-mode systems are the, different control plans are embraced in these two OM areas. In other words, in the OM district I, the vector's stage point remains unchanged, but its sufficiency is altered. To ensure a constant output VV into OM district II, beginning of this stage In addition, the vector's abundances has changed dramatically. The following diagram illustrates the dual-mode methodology's basic concept. The VV is constrained toward hexagonal limit without affecting the period of VV into the OM area I. This is the compensated output VV, whose sufficiency is more than the abundancy of the $\mathrm{o} / \mathrm{p} \mathrm{VV}$, which compensates for the voltage vector's tragedy abundancy. This reference stage point in the OM area II can govern the dynamic point for the repaid voltage vector. This complete VV direction (blue strong line) is visible in fig 5 .

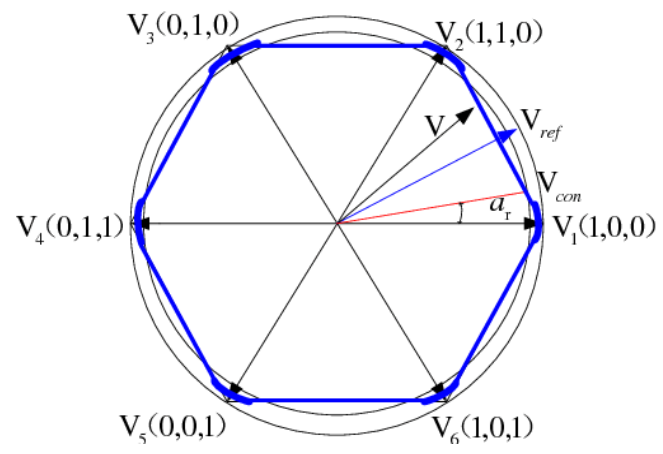

Fig. 5 Dual-mode OM area I VV trajectory [19]

With the help of Fourier modification, the output terminals voltage magnitude can be conveyed as an element of the starting point $a_{r}$. The link between $a_{r}$ and $\mathrm{m}$ can be found using the volt-second equilibrium guideline. To begin, the optimum output essential voltage amplitude determines the modulation coefficient and the corresponding reference stage point. When using the basis stage point, the abundances for this remunerated VV is determined. Lastly, the direction of the output VV is modulated by the magnitude of the remunerated VV. In any scenario, ar and $\mathrm{m}$ should be modified to online computation for the modulation cycle due to their nonlinear relationship. The inverter enters the $\mathrm{OM}$ area II if $\mathrm{m}$ is greater than 0.9517 , therefore the OM area I technique is no more accurate. Regulating the fundamental VV of the space vector is how the OM 
district II recompense job is done. This fundamental VV's successful stage point is bound by retaining point $\mathrm{a}_{\mathrm{r}}$. Fig 5 shows the VV's direction (blue strong line). The real o/p VV is kept up as this essential VV in this keeping point $a_{r}$. When the reference VV's electric point is set to $a_{h}$, the actual o/p VV starts to follow the reference $\mathrm{VV}$ and moves away from the basic VV.The link b/w reference voltagemaintaining points and staging point is known to be pursuing one another, and the stage change is steady, as illustrated above. Although the abundancies and stage of the o/p VVs were changed in the OM zone II, A positive link between $a_{r}$ and $m$ is still positive. The cycle's actualization method is the same as that of the OM area I. As in OM area II, the orientation of the $\mathrm{o} / \mathrm{p} \mathrm{VV}$ is significantly moved from the hexagon margin to the six-stage approach.

\subsection{Piece-wise fitting OM strategy}

Dual-mode OM calculation includes, obstructions of complex calculation, a large number of detached information figuring, and greater requirements for equipment gadgets in the measurement uses as overmodulation research develops. In light of the classic dual-mode hypothesis [19], a piecewise-fitting OM computation is persented [20] to address the foregoing difficulties. The fundamental rule is as explained: if the framework's reference $\mathrm{o} / \mathrm{p}$ voltage is between the span of the distracting loop and the span of the encircled hover for the enormous hexagon, which is shown in Figs 4 and 5, the framework is overmodulated. The abundantness for this reference VV is initially customized in the OM zone I. The control point is explained like the intersection of the reference $\mathrm{o} / \mathrm{p} \mathrm{VV}$ 's abundancy direction and the large standard hexagon. Finally, the numerical relationship among the modulation-coefficients or the control point is presented using the mathematical link. Furthermore, the piecewise direct fitting has been completed for it. In comparison to the dual-mode system, the presented strategy not just to saves the framework's activity season, but it as well save the complicated fundamental link. Using the voltsecond-equilibrium standards or the amplitude of that same adjusted reference $\mathrm{VV}$, the abide season of every switches is estimated.

Because the pay in the district I is not significant at this moment, the calculation in over-modulation area II, that is revised many times. That is to say, this reference $\mathrm{VV}$ is kept up into a timeframe into a big hexagonal vertex and after that goes with the edge in the OM area II to obtain the reason behind abundancy $2^{\text {nd }}$ remuneration. Because the reference vector is spent some time at the vertices for a huge hexagonal, the point at the vertices is labeled at holding point, which defines the appropriate time for this to stay. The variation between areas I and II is this. In terms of the completed modulation scheme, the retaining point's range is $(0,6)$ in this case. When its reaches $\Pi / 6$, the framework enters the constant voltage zone
$\&$ begins operating through 6 stages of wave levels. Whenever the position of the vector is within 0 and $a_{h}$, the genuine measured voltage lags in after the supreme measured $\mathrm{VV}$. When the vector point is among $\Pi / 3-a_{h}$ and $\Pi / 3$, this is in the presence with the suitable reference VV. These remaining phases are equal to the system of OM area I, hence they aren't shown here.

\subsection{OM approach based on super-position principle.}

For avoid the drawbacks of typical dual-mode systems, such as computationally unpredictability and inconvenient usage, as well as presented an OM approach according to super-position strategy. According to the dual-mode system's guidelines, the $\mathrm{OM}$ area is separated into two sections. That's all there is to modulation areas I and II. Two modulation areas have a fundamental balancing coefficient of 0.9520. The major difference between the modern and conventional techniques.

i. The modulation factor $\mathrm{m}$, be still re-imagined.

ii. The elective reference VV is combined through two section VVs.

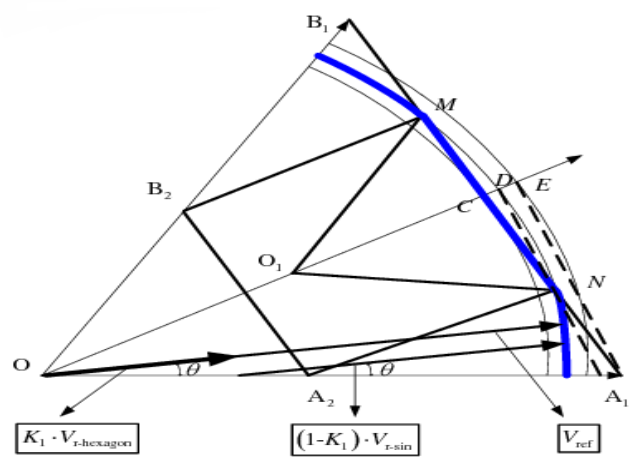

Fig. 5 superimpose modulation strategy among OM area 1[22]

Into the $\mathrm{OM}$ area 1 the superposition weight coefficient $\mathrm{k} 1$ is defined as:

$$
K_{1}=\frac{(m-0.907}{0.952-0.907}
$$

OC stands for the magnitude of the reference voltage vector in an $\mathrm{OM}$ area $\mathrm{I}$, and it corresponds to the largest straight adjustment proportion. In a similar modulation area, OD is the reference voltagearbitrary vector's abundancy that wouldn't need to be modified for stage point. The probable esteem direction for the reference VV, suspension of the big usual hexagon's internal digression, and the hover of the range of the enormous vector magnitude among OM I area, as per the dual-mode OM method. The super-position guideline can mix the true reference vector along these lines. Fig 6 [22] depicts the superposition cycle. (into fig 6 , genuine direction for reference VV appears as a blue strong line.) A direct modulation area's most extreme output $\mathrm{VV}$ is defined.

$$
V_{r_{-} \sin }=o c \cdot e^{j \theta}=\left(\frac{V_{d c}}{\sqrt{3}}\right) \cdot e^{j \theta}
$$




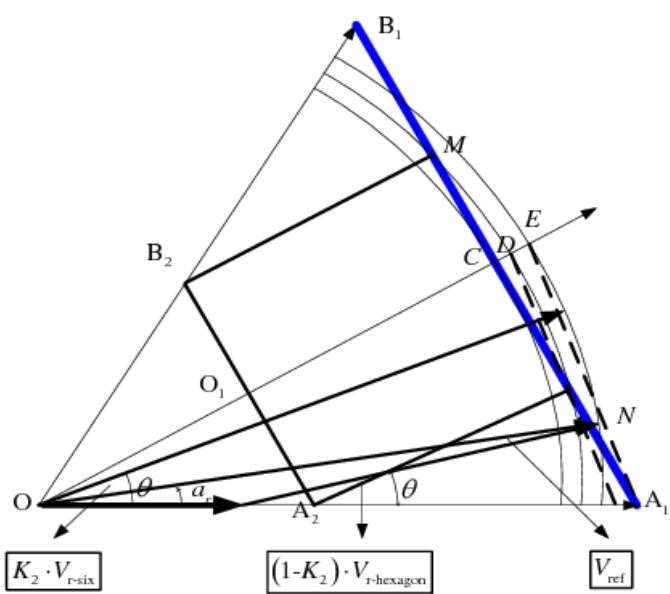

Fig. 7 Synthesis principle diagram of super-position OM strategy in OM area II. [22]

The stay season of the fundamental vectors can also be computed using the volt second equilibrium rule. Developed another OM technique by Yang et al [22] Based on their examination of OM approach in light of the superposition rule. In comparison to the modern dual-mode methodology, having several benefits, as an example dramatically enhancing coherence, avoiding muddled disconnected calculation and query measures, and so on. Sophisticated processors' computation time is greatly reduced, and the technique's repeatability is greatly improved. In addition, the technique allows the framework to easily move from direct modulation to waveform while successfully controlling the Harmonic distortion of resultant voltage [18]. Create a modern OM system based on the superposition standard that can successfully raise the amplitude move proportion of the inverter. The persented overmodulation system is based on a superposition strategy [35]. Not only does it produce a similar presentation as piece-wise fitting, also it has a superior recurring frequency. This is far from tough to grow and materialise the system in this manner.

\subsection{OM (Over-Modulation) techniques for Open- loop control approches}

Only with the rising use of DC power, there has been a series of OM-related challenges that need to be addressed. As an example, multifarious nature of calculating, the incorrect direction of attracting areas, or presentation of music as a result of a VV change. Regardless, open-loop \& closed-loop control OM methodologies are presented of whether the controlling cycle has the close-up. the close loop. The open-loop OM methodology's control concept is a balancing between the procedure's complication and the control exactness within the OM area. In the beginning, the exemplary dual-mode system was an open-loop SV-PWM OM technology that used feedforward. The approach having a few flaws, as an example, it cannot be linearized when it comes to controlling point alteration.

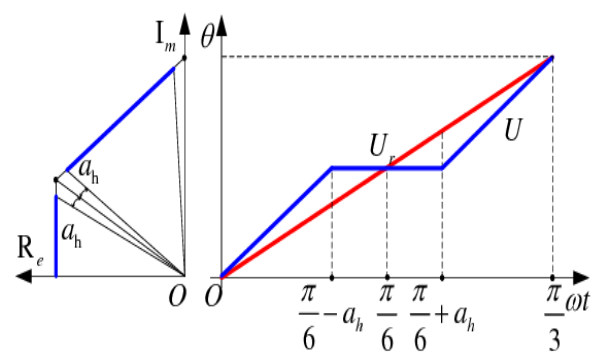

(a) Conventional dual-mode over modulation region voltage vector phase diagram

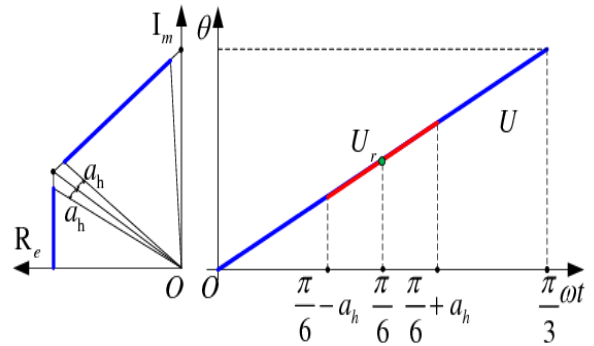

(b) Optimized dual-mode over modulation region voltage vector phase diagram

Fig. 8 Phase optimization comparison chart [25]

The shortfall isn't useful for designing and doesn't take into account the huge equilibrium [25]. The voltage output of its framework under the OM method with stage variation has a far more consistent substance as compared to the sufficient enhancement approach. As a result of the above-mentioned, the modern open-loop OM process is boosted by [25]. The standard for change is to improve the plan's execution without changing the stage. However. The VV stage modulation technique in the OM area II has been changed to a stage bounce method due to the complexity of the measurement technique. Under use of low voltage $\mathrm{o} / \mathrm{p}$ exactness, this can untangle the stage suitably. In the stage modification approach, the output VV be bounced to match the measured voltage upon the maintenance position. Fig 8 depicts a differentiation outline of earlier, then after the fact stage improvement.

\subsection{Close loop over-modulation strategy}

This close-loop OM methodology is offered to address the issues of open-loop technology, for example control-precision, figuring cycle, or memory. These output voltage-sufficiency vector's can be naturally varied. In the close loop control framework by the feedback loop. Under the closeloop control framework, the direction of the VV would be naturally formed in the balance measure. Furthermore, deciding the plentifulness for the remunerated $\mathrm{VV}$ as suggested in the form of a 
reference point isn't necessary. The SV-PWM OM method is improved [24], [26] when the quality of $\mathrm{VV}$ programmed remuneration is used in the near loop control framework. Also, in any event, the balancing area II control process has not been significantly enhanced. Due to the deficiencies listed above, the current close loop process has been improved [25]. The direction of the o/p VV in the OM area-I is equal to the enhanced $\mathrm{OM}$ technique and the exemplary dual-mode methodology corresponding with close-loop controlling qualities within OM area II. What matters is which concepts for a reference point \& a pay VV aren't included. The following is the essential rule of the advanced closed-loop control OM system. The close loop input shifts the reference $\mathrm{VV}$ amplitude range from $\mathrm{Vdc} \Pi / 3$ to $2 \mathrm{Vdc} \Pi / 3$. Simultaneously, the corresponding real output voltage vector's basic wave abundancy ranges from $(\mathrm{Vdc \Pi} / 3)$ to $0.9517 \cdot(2 \mathrm{Vdc} / \Pi)$. The ideal closed-loop methodology's measured voltage differs from the dual-mode procedure's boost inverter in several respects. That is, instead of anticipating the o/p VV, the prior method generates a progress $\mathrm{VV}$, which is then use to produce true VV directions within feedback guidance. If the load on the framework is enhanced to a particular amount, this framework enters the $\mathrm{OM}$ district. These results in negative feedback the reference voltage vectors sufficiency can be increased using the voltage controller. The SV-PWM modulator can achieve the reason for changing the reference $\mathrm{VV}$, as illustrated by the control mechanism exposed into Fig.9.

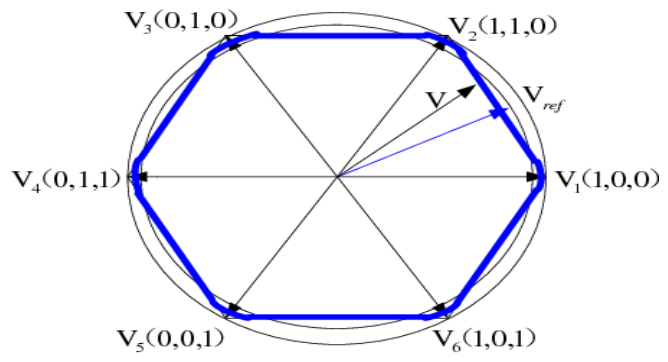

Fig. 9 OM area I VV trajectory [26]

This extent of the VV should be changed and the VV stage should be changed in OM area II since this framework into profound OM express. That changing in the voltage stage could not disentangle as a hopping mode since the exactness of the attractive field direction must be considered. As a result, the period of the VV should be altered continuously for decreasing disturbing influence for $\mathrm{o} / \mathrm{p}$ current or its effect on controlling the framework. This is a dualmode OM process is used in the OM area II. Nonetheless, the measured voltage vector's association problem requires consideration in $\mathrm{OM}$ regions I \& II. In other words, o/p voltage vectors plentifulness changed from $0.9517(2 \mathrm{Vdc} / \Pi)$ to $2 \mathrm{Vdc} / \Pi$ as the adjusted magnitude for the current- loop is changed from $0.9517 * 2 \mathrm{Vdc} / 3$ to $2.2 \mathrm{Vdc} \Pi / 3$, bringing the framework for the functioning state of the six-stage stepping stool [25].

\section{OM (OVER MODULATION) STRATEGY FOR CSI}

The fundamental technique for CSI- SV-PWM-OM operation is discussed as following:

If the reference current-vector increases to the hexagon's limit, this framework can no longer be modified normally. As a result, the over-modulation system must make proper acclimations to the overabundance section of the vector. In practice, the use of reference $\mathrm{o} / \mathrm{p}$ voltage is an important factor for consideration when evaluating this display for CSImodulation [36]. This compelling adjustment coefficient $\mathrm{m}$ can be used to depict the utilization of DC current. The $\mathrm{m}$ is the modulation coefficient which is defined by $\mathrm{I}_{\mathrm{o}} / \mathrm{I}_{\mathrm{dc}}$ to determine the CSI OM profundity. The abundancy of the output stage current is Io, while the DC- current is Idc. With the growth of current technology, CSI is now paying greater attention to the Uninterruptible Power Supply (UPS) [37]-[39], photovoltaic force age framework [40-41], microgrid framework [42]-[44], and other disciplines. A proper OM approach should be considered into order to an increase this use of DCcurrent. For CSI SV-PWM OM, there are now two basic approaches.

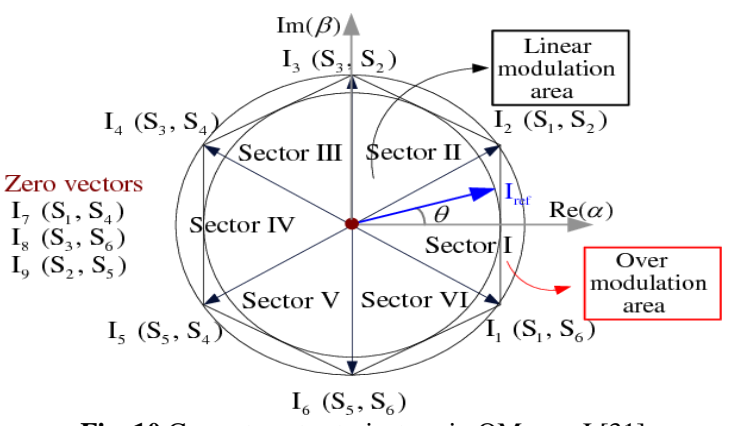

Fig. 10 Current vector trajectory in OM area I [31]

i. The VSI's typical dual-mode OM technology is used in the CSI's dual-mode OM methodology.

ii. Block OM system.

Each of the previous systems are employed on a three-level CSI, but staggered CSI OM must be calculated as well.

\subsection{A. Dual-mode OM (Over-Modulation)}

Based on the duality among VSI \& CSI regarding SV-PWM, Long-Cheng in [45]-[48] refined the dualmode OM system of VSI and formally approved it to CSI. The following is the basic specification for the CSI dual-mode OM technology. The overmodulation area is divided into two areas, as shown in Fig. 2, and the meaning of the balance coefficient with CSI. 
i. The framework output current central wave segment's most extreme pinnacle estimation is $I_{d c}$ when $m$ is 1 .

ii. When $\mathrm{m}$ equals 1.1 , the framework is overmodulated, and the output current is maximum. Six heartbeat waves are the current running state. When all factors are considered, the over-modulation area $\mathrm{I}$ is defined if $\mathrm{m}$ varies among $1 \& 1.05$. OM area II is explained if $\mathrm{m}$ varies among 1.05 $\& 1.1$.

\subsubsection{OM area I}

Among modulation area I, phase difference for the reference current -component $\mathrm{I}_{\text {ref }}$ being constant, but the magnitute must be adjusted suitably. Fig 11 depicts the path of the modified reference- current vector $\mathrm{I}$. $\mathrm{I}=\mathrm{I}_{\text {ref }}$ at the (as seen from Fig 11.) about the concerning the hexagon's periodic termination.

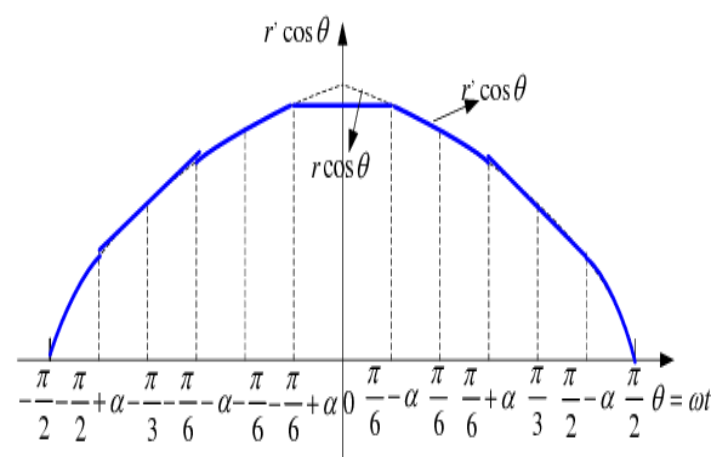

Fig. $11 \mathrm{OM}$ area I later than the vary from refrence current vector projection upon real- axis [32]

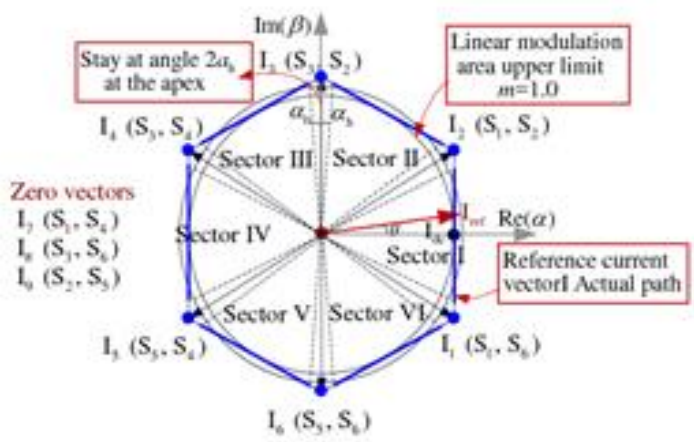

Fig. 12 Real track of reference current- vector after modulation area II change [32]

Here $r$ denotes this reference current vector's hover span, and which is intersection for reference currentvector.

\subsubsection{OM area II}

Stage point or sufficiencies for reference currentvector are altered suitably in OM district II. In Fig 13, the trace for changing reference-current- vector I can be seen (the blue thick strong line). For a length of time, the $\mathrm{o} / \mathrm{p}$ current-vector will remain every hexagonal termination. The intersection of the reference-current-vector \& this vector toward the termination guide, as shown in Fig 13. At number 13, the o/p current- vector continued to move beside the hexagon limit. The projection of the authentic reference vector I on the genuine pivot is shown in Fig 13.

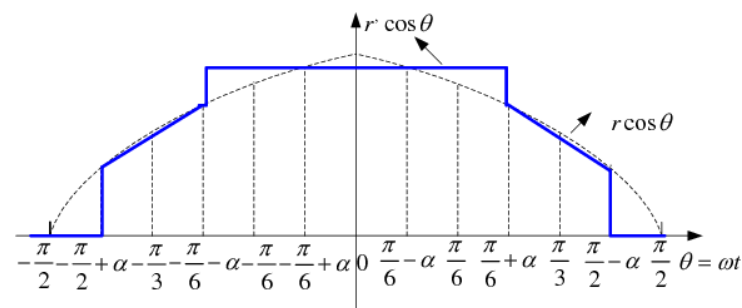

Fig. 13 Projection for refrence current vector later than the modulation area I changes lying on real axis [32]

This true reference vector's Fourier study has been completed, and its basic part can be obtained. The adjustment coefficient $\mathrm{m}$ can also be obtained at this stage. CSI's dual-mode OM approach is finally confirmed in. this is not only understood seamless transition among direct \& over-modulated districts, it having the advantage of low $\mathrm{o} / \mathrm{p}$ symphonious materials. Also, if used in UPSs that use a CSI, this framework would reduce the unsettling effect of direct current and improve the framework's dynamic reaction speed, as well as increasing the framework's output power. Regardless, there are a few flaws in this approach, such as computing complexity and the requirement for numerous disconnected information estimations in the execution measure. As a result, the equipment offices will face a number of challenges as a result of this plan. The technique needed to be upgraded because it had not been tested in the study.

\section{A. Block-OM strategy:-}

To solve the drawbacks for CSI dual-mode OM technique, a square OM approach was presented by [33],[49]-[52]. The approach offers a few advantages, such as saving hard loop capacity space and eliminating the need for unpredictable calculations. As a result, it is perfectly normal to use a single FPGA. A test with a high transient state reaction and a consistent state reaction demonstrates this. This method allows the framework to maintain the activity of the solidarity power factor while lowering the total harmonic distortion of lattice current over a wider range of $\mathrm{DC} \mathrm{o} / \mathrm{p}$. Sector II defines the essential standard of the CSI block OM technique, and the rest of the areas are divided in the same way.

i. If reference-vector $I_{A}$ is in subsystem.

ii. The stay time between the powerful vectors is $\mathrm{T} 1>\mathrm{TS}>\mathrm{T} 2$. Only the powerful vector I1 is active at the moment, and referencecurrent real directions are interrupted at termination point $\mathrm{C}$.

iii. Connection of the abide time about the successful vectors is $\mathrm{T} 1+\mathrm{T} 2>\mathrm{TS}$ and $\mathrm{T} 1>$ $\mathrm{T} 2$ if reference-vector IB is placed into a subsystem (1). As a result, the powerful 
vectors $I_{1}$ and $I_{2}$ can be selected to do a task. There are now two modes for controlling the reference current. Both examples $\mathrm{A}$ and design $B$ have their own distinct characteristics. Mode A has an $\mathrm{I}_{\mathrm{b}}$-produced current vector. $\mathrm{I}_{0 \mathrm{~b}}$ is the produced current vector for mode $\mathrm{B}$.

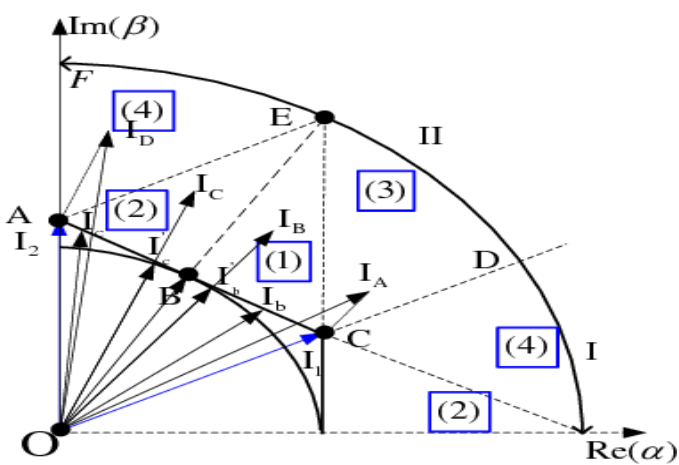

Fig 14: CSI block OM strategy vector diagram [33]

iv. If the module's reference-vector $\mathrm{I}_{\mathrm{C}}$ is available in place (2), T1 +T2 > TS and T2 $>\mathrm{T} 1$ are the connections of the abide time about the successful vectors. In this vein, the successful vectors I1 and I 2 can be selected to take on a job. The reference-current is now be controlled in 2 ways. Both examples $\mathrm{A} \& \mathrm{~B}$, as well as design $\mathrm{B}$, are described separately. Mode A's designed current vector is Ic. $\mathrm{I}_{0 \mathrm{c}}$ is the produced current vector in mode $B$.

v. The connection of the abide time regarding the successful vectors is T2 $>\mathrm{TS}>\mathrm{T} 1$ If the resultant -vector ID is placed in the subsystem (4). Only all successful vector $\mathrm{I}_{2}$ is currently active, and the reference current real direction is currently paused at endpoint A.

\section{CONCLUSION}

The continued development for OM systems of both VSI \& CSI was examined in this research. During previous years, a plethora of fascinating combinations is introduced here. Furthermore, a evaluation of each system's preferences and flaws energy is the good presenting method for the client. As a result, research into current source inverter overmodulation systems is still a long way off from being developed, compared to VSI. CSI will become increasingly significant as broad range hole semiconductors, like the cost-effective $\mathrm{SiC} \& \mathrm{GaN}$ power components, gain in popularity. As a result, future research into the ebb and flow source inverter's OM technique would be an interesting topic.

\section{REFERENCES}

[1] Zhou, Zhenyu et al. "Game-Theoretical Energy Management for Energy Internet with Big Data-Based Renewable Power Forecasting". IEEE Access, vol 5, (2017), pp. 57315746. Institute of Electrical and Electronics Engineers (IEEE), doi:10.1109/access.2017.2658952.

[2] Al Haj Hassan, Hussein et al. "Integrating Cellular Networks, Smart Grid, and Renewable Energy: Analysis, Architecture, and Challenges". IEEE Access, vol 3, (2015), pp. 27552770. Institute of Electrical and Electronics Engineers (IEEE), doi:10.1109/access.2015.2507781.

[3] Reddy, Damodhar, and Sudha Ramasamy. "Design of RBFN Controller Based Boost Type Vienna Rectifier for Grid-Tied Wind Energy Conversion System". IEEE Access, vol 6, (2018), pp. 3167-3175. Institute of Electrical and Electronics Engineers (IEEE), doi:10.1109/access.2017.2787567.

[4] Gupta, A.K., and A.M. Khambadkone. "A Space Vector PWM Scheme for Multilevel Inverters Based On Two-Level Space Vector PWM". IEEE Transactions on Industrial Electronics, vol 53, no. 5, (2006), pp. 1631-1639. Institute of Electrical and Electronics Engineers (IEEE), doi:10.1109/tie.2006.881989.

[5] Deng, Yi, and Ronald G. Harley. "Space-Vector versus Nearest-Level Pulse Width Modulation for Multilevel Converters". IEEE Transactions on Power Electronics, vol 30, no. 6, (2015), pp. 2962-2974. Institute of Electrical and Electronics Engineers

(IEEE), doi:10.1109/tpel.2014.2331687.

[6] Jae Hyeong Seo et al. "A New Simplified Space-Vector PWM Method for Three-Level Inverters". IEEE Transactions on Power Electronics, vol 16, no. 4, (2001), pp. 545-550. Institute of Electrical and Electronics Engineers (IEEE), doi:10.1109/63.931078

[7] Mahmoud, Zouhaira Ben et al. "Space Vector Modulation of Multilevel Inverters: A Simple and Fast Method of TwoLevel Hexagon's Selection". International Journal of Power Electronics, vol 8, no. 2, 2017, p. 107. Inderscience Publishers, doi:10.1504/ijpelec.2017.082932.

[8] Keliang Zhou, and Danwei Wang. "Relationship between Space-Vector Modulation and Three-Phase Carrier-Based PWM: A Comprehensive Analysis [Three-Phase Inverters]". IEEE Transactions on Industrial Electronics, vol 49, no. 1, (2002), pp. 186-196. Institute of Electrical and Electronics Engineers (IEEE), doi:10.1109/41.982262.

[9] Holtz, J. "Pulsewidth Modulation-A Survey". IEEE Transactions on Industrial Electronics, vol 39, no. 5, (1992), pp. 410-420. Institute of Electrical and Electronics Engineers (IEEE), doi:10.1109/41.161472.

[10] T. A. Bernardes, H. Pinheiro, and V. F. Montagner, "PMSG current control in the over-modulation area,"' in Proc. 35th Annu. Conf. IEEE Ind. Electron., Nov. (2009), pages 16871692.

[11] Hee-Jhung Park, and Myung-Joong Youn. "A New TimeDomain Discontinuous Space-Vector PWM Technique in Overmodulation Region". IEEE Transactions on Industrial Electronics, vol 50, no. 2, (2003), pp. 349-355. Institute of Electrical and Electronics Engineers (IEEE), doi:10.1109/tie.2003.809402.

[12] Lee, Kyo-Beum, and Frede Blaabjerg. "An Improved DTCSVM Method For Sensorless Matrix Converter Drives Using An Overmodulation Strategy And A Simple Nonlinearity Compensation". IEEE Transactions on Industrial Electronics, vol 54, no. 6, (2007), pp. 3155-3166. Institute of Electrical and Electronics Engineers (IEEE), doi:10.1109/tie.2007.905914.

[13] Lee, Kyo-Beum, and Frede Blaabjerg. "An Improved DTCSVM Method For Sensorless Matrix Converter Drives Using An Overmodulation Strategy And A Simple Nonlinearity Compensation". IEEE Transactions on Industrial Electronics, vol 54, no. 6, (2007), pp. 3155-3166. Institute of Electrical and Electronics Engineers (IEEE), doi:10.1109/tie.2007.905914.

[14] Bolognani, S., and M. Zigliotto. "Novel Digital Continuous Control of SVM Inverters in the Overmodulation Range". IEEE Transactions on Industry Applications, vol 33, no. 2, (1997), pp. 525-530. Institute of Electrical and Electronics Engineers (IEEE), doi:10.1109/28.568019. 
[15] Dujic, D. et al. "A Space Vector PWM Scheme for Multifrequency Output Voltage Generation with Multiphase Voltage-Source Inverters". IEEE Transactions on Industrial Electronics, vol 55, no. 5, (2008), pp. 1943-1955. Institute of Electrical and Electronics Engineers (IEEE), doi:10.1109/tie.2008.918468

[16] Kim, Joohn-Sheok, and Seung-Ki Sul. "A Novel Voltage Modulation Technique of the Space Vector PWM." IEEJ Transactions on Industry Applications, vol 116, no. 8, (1996), pp. 820-825. Institute Of Electrical Engineers Of Japan (IEE Japan), doi:10.1541/ieejias.116.820.

[17] Zhenghua Xu, Dongliang Liu, Xiaodan Zhao, Jinsong Ren. Over modulation control strategy of Space vector PWM review, Chinese Control and Decision Conference (CCDC), 28-30, May 2016, pages 3192-3196.

[18] Ze Li., Yuanbo Guo., Kai Huang. Xiaohua Zhang. et al.: 'Synchronized SV-PWM strategy based on superposition principle for the OM area at low switching frequency', 19th International Conference on Electrical Machines and Systems (ICEMS), Nov. (2016), pages 1-6.

[19] Holtz, J. et al. "On Continuous Control of PWM Inverters in the Overmodulation Range Including the Six-Step Mode". IEEE Transactions on Power Electronics, vol 8, no. 4, (1993), pp. 546-553. Institute of Electrical and Electronics Engineers (IEEE), doi:10.1109/63.261026.

[20] Dong-Choon Lee, and G-Myoung Lee. "A Novel Overmodulation Technique for Space-Vector PWM Inverters". IEEE Transactions on Power Electronics, vol 13, no. 6, (1998), pp. 1144-1151. Institute of Electrical and Electronics Engineers (IEEE), doi:10.1109/63.728341.

[21] Li, Shanhu et al. "A Multimode Space Vector Overmodulation Strategy for Ultrasparse Matrix Converter with Improved Fundamental Voltage Transfer Ratio". IEEE Transactions on Power Electronics, vol 33, no. 8, (2018), pp. 6782-6793. Institute of Electrical and Electronics Engineers (IEEE), doi:10.1109/tpel.2017.2752748.

[22] Dong-Choon Lee, and G-Myoung Lee. "A Novel Overmodulation Technique for Space-Vector PWM Inverters". IEEE Transactions on Power Electronics, vol 13, no. 6, (1998), pp. 1144-1151. Institute of Electrical and Electronics Engineers (IEEE), doi:10.1109/63.728341.

[23] Lu, Jing, and Ming Shen. "Research on Limit-Trajectory Over-Modulation Strategy of Two Stage Matrix Converter". Applied Mechanics and Materials, 599-601, (2014), pp. 1648-1651. Trans Tech Publications, Ltd., doi:10.4028/www.scientific.net/amm.599-601.1648.

[24] Park, Yongsoon et al. "Linear Overmodulation Strategy for Current Control in Photovoltaic Inverter". IEEE Transactions on Industry Applications, vol 52, no. 1, (2016), pp. 322-331. Institute of Electrical and Electronics Engineers (IEEE), doi:10.1109/tia.2015.2472518.

[25] Wan Shiyuan, SVPWM over modulation strategy research and implementation, Master's thesis, Huazhong University of Science and Technology, 2014.

[26] Casadei, D. et al. "Matrix Converter Modulation Strategies: A New General Approach Based On Space-Vector Representation of the Switch State". IEEE Transactions on Industrial Electronics, vol 49, no. 2, (2002), pp. 370381. Institute of Electrical and Electronics Engineers (IEEE), doi:10.1109/41.993270.

[27] Shun Jin, Yaoru Zhong, A novel three-level SV-PWM strategy considering neutral-point control, narrow-pulse elimination and deadtime compensation, The 4th International Power Electronics and Motion Control Conference. IPEMC, Aug. 2004, pages 688-693.

[28] Jin Sik Park, Shin Myoung Jung, Hag Wone Kim, et al, A Study on Stable Torque Control in Over-modulation Area for High Speed PMSM Systems, PESC2008, IEEE, 2008, pages 2373-2377

[29] Wu Bin.: 'High-power inverter for AC drives', IEEE PressWiley, 2006.

[30] Biswas, Sujit K. et al. "A New PWM Control Method for Three-Phase Autosequentially Commutated Current Source Inverters". IEEE Transactions On Industry Applications, vol -23 , no. 3, (1987), pp. 554-560. Institute of Electrical and
Electronics

Engineers

(IEEE), doi:10.1109/tia.1987.4504945.

[31] Espinoza J, Joos G, Jin H, DSP based space vector PWM Pattern generators for current source rectifiers' inverter, Conadian Conference on Electrical and Computer Engineering, Canada, 1995.

[32] Lei, Qin, and Fang Zheng Peng. "Space Vector Pulsewidth Amplitude Modulation for a Buck-Boost Voltage/Current Source Inverter". IEEE Transactions on Power Electronics, vol 29, no. 1, (2014), pp. 266-274. Institute of Electrical and Electronics Engineers (IEEE), doi:10.1109/tpel.2012.2225847.

[33] Chunyu Zhang, Yabin Li, Qi Wang, et al. , The implementation and analysis of OM technique of three-phase current source rectifier based on FPGA, IEEE Trans. Power. India Conference, Oct.2008, pages 1-7.

[34] Li, Y., Yonglong Peng, Heming Li, OM technique of threephase voltage source inverter based on FPGA, 2007 2nd IEEE Conf. Ind, 2007.

[35] Wang Weijie., Research and implementation of SV-PWM strategy for three-level inverter in full-modulation range, Master's thesis, Southwest Jiaotong University, 2015.

[36] Bin Wu, Mehdi Narimani, PWM Current Source Inverters, 'High-Power Inverters and AC Drives, Wiley-IEEE Press, 2017.

[37] Zhang, Yu et al. "Simplified Model and Control Strategy of Three-Phase PWM Current Source Rectifiers for DC Voltage Power Supply Applications". IEEE Journal of Emerging and Selected Topics in Power Electronics, vol 3, no. 4, (2015), pp. 1090-1099. Institute of Electrical and Electronics Engineers (IEEE), doi:10.1109/jestpe.2015.2421339.

[38] Sato, Y. "Simplified Control Strategy to Improve AC-InputCurrent Waveform of Parallel-Connected Current-Type PWM Rectifiers". IEE Proceedings - Electric Power Applications, vol 142, no. 4, (1995), p. 246. Institution of Engineering and Technology (IET), doi: 10.1049/ip-epa: 19951809.

[39] Bing, Zhonghui et al. "Control Of Three-Phase PWM Rectifiers Using A Single DC Current Sensor". IEEE Transactions on Power Electronics, vol 26, no. 6, (2011), pp. 1800-1808. Institute of Electrical and Electronics Engineers (IEEE), doi:10.1109/tpel.2010.2070809.

[40] Guo, Xiaoqiang. "Three-Phase $\mathrm{CH} 7$ Inverter with a New Space Vector Modulation to Reduce Leakage Current for Transformerless Photovoltaic Systems". IEEE Journal of Emerging and Selected Topics in Power Electronics, vol 5, no. 2, (2017), pp. 708-712. Institute of Electrical and Electronics Engineers (IEEE), doi:10.1109/jestpe.2017.2662015.

[41] Freddy, Tan Kheng Suan et al. "Modulation Techniques To Reduce Leakage Current In Three-Phase Transformerless H7 Photovoltaic Inverter". IEEE Transactions on Industrial Electronics, vol 62, no. 1, 2015, pp. 322-331. Institute of Electrical and Electronics Engineers (IEEE), doi:10.1109/tie.2014.2327585.

[42] Guo, Xiaoqiang et al. "Space Vector Modulation for DCLink Current Ripple Reduction in Back-To-Back CurrentSource Converters for Microgrid Applications". IEEE Transactions on Industrial Electronics, vol 62, no. 10, (2015), pp. 6008-6013. Institute of Electrical and Electronics Engineers (IEEE), doi:10.1109/tie.2015.2424397.

[43] Guo, Xiaoqiang et al. "Optimal Space Vector Modulation of Current-Source Converter for DC-Link Current Ripple Reduction". IEEE Transactions on Industrial Electronics, vol 66, no. 3, (2019), pp. 1671-1680. Institute of Electrical and Electronics Engineers (IEEE), doi:10.1109/tie.2018.2835396.

[44] Majumder, Ritwik. "A Hybrid Microgrid with DC Connection at Back To Back Converters". IEEE Transactions on Smart Grid, vol 5, no. 1, (2014), pp. 251259. Institute of Electrical and Electronics Engineers (IEEE), doi:10.1109/tsg.2013.2263847.

[45] Fang, Fanxiu et al. "A New Space Vector Modulation Strategy to Enhance AC Current Quality of Isolated DC-AC Matrix Converter". IEEE Transactions on Industry 
Applications, vol 57, no. 3, (2021), pp. 2602-2612. Institute of Electrical and Electronics Engineers (IEEE), doi:10.1109/tia.2021.3056493.

[46] Dang, Hoang-Long et al. "Reduction of DC Current Ripples by Virtual Space Vector Modulation for Three-Phase ACDC Matrix Converters". Energies, vol 12, no. 22, (2019), p. 4319. MDPI AG, doi: 10.3390/en12224319.

[47] Behera, Kuldeep, and Subrat Behera. "A Novel Control Strategy of Indirect Matrix Converter Using Space Vector Modulation". International Journal of Power Electronics and Drive Systems (IJPEDS), vol 7, no. 3, 2016, p. 926. Institute of Advanced Engineering and Science, doi:10.11591/ijpeds.v7.i3.pp926-935

[48] L. Tan, Y. Li, and P. Wang, An overmodulation method for space vector PWM current source inverters, in Proc. 2nd Conf. IEEE Trans. Ind. Appl., May 2007, pages. 2431-2434.

[49] Hu, Wang et al. "A Novel Three-Phase Current Source Rectifier Based On an Asymmetrical Structure to Reduce
Stress on Semiconductor Devices". Energies, vol 13, no. 13, 2020, p. 3331. MDPI AG, doi: 10.3390/en13133331.

[50] Tanaka, Toshihiko et al. "An Active-Passive CapacitorCommutated Converter for HVDC Systems with a ThreePhase Voltage-Source PWM Converter". Electrical Engineering in Japan, vol 151, no. 1, (2005), pp. 6675. Wiley, doi:10.1002/eej.20030.

[51] C. Zhang, Y. Li, Q. Wang, and C. Li, The optimal control policies of three-phase current source rectifier based on overmodulation technique, in Proc. 2nd IEEE Conf. ICIEA, Dec. 2009 , pages. $1-5$.

[52] Wilsun Xu et al. "A Three-Phase Converter Model for Harmonic Analysis of HVDC Systems". IEEE Transactions on Power Delivery, vol 9, no. 3, 1994, pp. 17241731. Institute of Electrical and Electronics Engineers (IEEE), doi:10.1109/61.311188. 